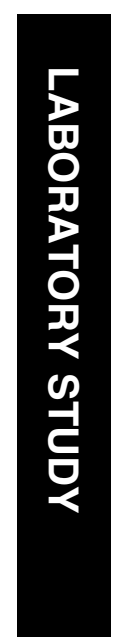

'Department of Ophthalmology Meir Hospital Sapir Medical Center Kfar-Saba, Israel

${ }^{2}$ Sackler School of Medicine Tel-Aviv University Tel-Aviv Israel

${ }^{3} \mathrm{QBI}$ Laboratories Ness-Ziona, Israel

${ }^{4}$ Goldschleger Eye Research Institute

Sheba Medical Center

Tel Hashomer

Israel

Correspondence: F Segev MD Department of Ophthalmology Toronto Western Hospital 7 Edith Cavell Wing Room 009399 Bathurst Street Toronto Ontario, Canada M5T 2S8

Tel: + 14166035800

ext: 2372

Fax:_1 4166036420

E-mail: fsegev@rogers.com

Received: 3 July 2003 Accepted: 28 November 2003

Published online: 23 April 2004

This work had been orally presented in part at the 2001 ARVO Annual meeting.

\section{Downregulation of gene expression in the ageing lens: a possible contributory factor in senile cataract}

F Segev ${ }^{1,2}, \mathrm{O} \mathrm{Mor}^{3}$, A Segev², M Belkin ${ }^{2,4}$ and El Assia ${ }^{1,2}$

\begin{abstract}
Purpose To study the molecular characteristics of lens epithelial cells from patients with senile cataract by cDNA microarray technique.

Methods Lens epithelial cells adhering to anterior capsules taken during cataract surgery collected from 108 patients, aged 56-92 years (senile cataract group), were pooled. Pooled epithelial cells of normal, noncataractous lenses from one patient with ocular trauma, one patient with lens subluxation, and 25 cadaveric eyes, all under the age of 55 years, served as a control. Total RNA was extracted by conventional methods from the two groups of cells, and a fluorescent probe was prepared for each group. The probes were hybridized on 9700 known human cDNA clones. Hybridized clones were analysed using a scanning laser and the results were processed by GEMTools (Incyte Genomics) software.
\end{abstract}

Results A total of 1827 clones hybridized with the two probes. Of these, 400 showed differences of more than two-fold in gene expression between the two probes. Relative to controls, gene expression in the senile cataract lenses was upregulated in 318 clones and downregulated in 82 . Three genesfilensin, inwardly rectifying potassium channel (IRPC), and pigment epitheliumderived factor (PEDF) were strongly downregulated (by 41.3-, 6.8-, and 5.9-fold, respectively) in senile cataract.

Conclusions Cataractogenesis is associated with numerous changes in the genetic profile of the lens epithelial cells. Since filensin, IRPC, and PEDF genes are known to have important roles in the physiology and morphology of the transparent lens, substantial downregulation of their expression might contribute to the formation of senile cataract.

Eye (2005) 19, 80-85. doi:10.1038/sj.eye.6701423

Published online 23 April 2004

Keywords: cataractogenesis; gene expression; filensin; potassium transport; PEDF

\section{Introduction}

The adult lens is a transparent, biconvex structure composed of one cell type, the lens epithelium. Epithelial cells at the anterior surface of the lens produce a basal membrane, the lens capsule, which coats the lens surface. The epithelial cells migrate towards the bow region of the lens, where they begin to undergo terminal differentiation into lens fibres, a process that includes the loss of all major organelles, massive cell elongation, and the expression of proteins specific to lens fibre cells. Normal lens metabolism requires an appropriate internal ionic-osmotic milieu, which in turn depends on communication between the epithelial cells and the lens fibres. Sodium/potassium-dependent ATPase channels are found at their highest concentration in the epithelium in order to maintain this unique milieu. ${ }^{1,2}$

The cytoplasm of the lens fibre cells (LFCs) contains crystallins, a class of water-soluble proteins believed to minimize scattering of the light that passes through it. The LFCs are organized in concentric layers connected by intercellular junctions. ${ }^{1,3}$ These cells possess a well-organized, spectrin-actin membrane cytoskeleton that consists of two different types of intermediate filaments: vimentin, which is spread throughout the cytoplasm, and 'beadedchain filaments', composed of the lens-specific 
proteins filensin and phakinin. Filensin, a 115-kD intermediate filament protein, is believed to be functionally important in LFC differentiation and in maintaining LFC conformation and transparency. ${ }^{4-6}$ Cell lines of murine and rabbit lenticular origin were shown to overexpress the filensin gene. ${ }^{7}$

Pigment epithelium-derived factor (PEDF), a 50-kDa secreted protein, is a member of the serpin family of proteins, and is expressed in all ocular tissues of the human eye. ${ }^{8}$ PEDF accumulates in the aqueous humour. ${ }^{9}$ It acts as a survival factor, protecting neuronal cells from natural and induced apoptosis. ${ }^{10}$

Lens function deteriorates with age. Oxidative stress, ultraviolet radiation, and other toxic factors can induce the formation of cataract in vitro and in vivo. ${ }^{1,11}$ The formation of senile cataract is a universal ageing process accompanied by numerous morphological and functional changes in the lens cells. This study was undertaken to investigate the molecular characteristic of lens epithelial cells from patients with senile cataract.

We started out with some basic assumptions. (a) The ageing process is manifested by DNA transcriptional changes, which result in alteration of protein expression. Thus, senile cataract is characterized by upregulation and downregulation of genes, manifested by over- or underexpression of their corresponding RNA species. These changes are detectable in senile cataractous lenses. (b) The ageing process eventually leads to cell death by either an active process of apoptosis (programmed cell death) or by senescence. Apoptosis of lens epithelial cells appears to be a common cellular basis for noncongenital cataract (including senile) development in humans and animals. ${ }^{12}$ (c) The lens is composed of one type of cell, the epithelium, and any genetic alterations will be expressed in these cells. (d) The epithelial cells adhere to the anterior capsule of the lens and can be extracted from there.

Since the number of lens epithelial cells from one individual is limited, we had to accumulate numerous samples and assume that they all share the same pathological pattern of senile cataract. Using microarraybased technology, which makes it possible to screen thousands of genes simultaneously, we analysed gene expression in the human cataractous lens.

\section{Methods}

\section{Patient data}

Lens epithelial cells adhering to anterior lens capsule taken during routine cataract surgery were collected, and the cells from 108 patients (62 women and 46 men), ranging in age from 56 to 92 years (mean age 74.6 years) were pooled (senile cataract group). The mean ages of the women and the men were 76.3 years and 72.2 , respectively. Exclusion criteria were age below 55 years, diabetes mellitus, pseudoexfoliation of the eye, traumatic cataract, a history of topical or systemic steroid treatment, and uveitic disease. During the week before cataract surgery patients underwent slit lamp examination and their cataracts were classified for the type and severity of the opacity by an experienced examiner according to Lens Opacities Classification Scale (LOC)-II grading system. ${ }^{13}$ Our senile cataract group consisted of $63 \%$ mixed cataract, $25 \%$ nuclear cataract, $7 \%$ cortical, and $5 \%$ posterior subcapsular. Anterior capsule-epithelium samples of 5-5.5 mm diameter were taken during surgery by capsulorhexis and were immediately washed by a balanced salt solution (BSS). Then, the capsules were placed in sterile tubes, immersed in liquid nitrogen at $-180^{\circ} \mathrm{C}$, and stored at $-80^{\circ} \mathrm{C}$.

The pooled epithelial cells adhering to the anterior lens capsules of normal, non-cataractous lenses from one patient with blunt ocular trauma who had undergone surgery for subluxated clear lens, one patient with essential subluxated lens, and 13 cadavers (25 eyes) (aged 2-54 years) served as a control. Clear whole lenses from organ donors were obtained within $12 \mathrm{~h}$ post mortem. The lenses were microscopically examined for opacities and those lenses displaying opacity were excluded from the study. The anterior capsules for central epithelium $\left(7-8 \mathrm{~mm}^{2}\right)$ were dissected and lens fibres removed to prevent contamination. The anterior capsules were placed in sterile tubes and immersed in liquid nitrogen at $-180^{\circ} \mathrm{C}$, and in a later stage were stored in $-80^{\circ} \mathrm{C}$.

\section{RNA extraction}

Total RNA was extracted by conventional methods from the epithelial cells adhering to the capsules. ${ }^{14-16}$ RNA was isolated using the Trireagent ${ }^{\mathrm{TM}}$ protocol. Briefly, $1 \mathrm{ml}$ of a mixture of guanidine thiocyanate and phenol in a mono-phase solution (Trireagent ${ }^{\mathrm{TM}}$ ) was added to every 10 frozen capsules. Following denaturation of proteins, bromochloropropane was added and the RNA was separated by centrifugation $\left(14000 \mathrm{~g}\right.$ for $10 \mathrm{~min}$ at $4^{\circ} \mathrm{C}$ ). The interphase containing DNA and the lower organic phase containing proteins were discarded, and total RNA was collected from the upper aqueous phase.

Isopropanol was added and the mixture was centrifuged at $12000 \mathrm{~g}$ for $15 \mathrm{~min}$ at $4{ }^{\circ} \mathrm{C}$. The RNA pellet was washed with $75 \%$ ethanol, vortexed, and repelleted by centrifugation at $7500 \mathrm{~g}$ for $5 \mathrm{~min}$ at $4{ }^{\circ} \mathrm{C}$. The final RNA pellet was air dried and dissolved in water by repeated pipetting for $10 \mathrm{~min}$ at $60^{\circ} \mathrm{C}$. RNA concentrations were measured by a spectrophotometer at $260 \mathrm{~nm}$. 
RNA quality was assessed by running $0.5-1 \mu \mathrm{g}$ of RNA on $1 \%$ agarose gels. Samples that were found to contain degraded RNA were discarded. Good-quality RNA from the 15 pooled noncataractous lenses yielding $50 \mu \mathrm{g}$ of total RNA (a sufficient amount for probe synthesis) and from a pooled sample of senile cataract lenses that yielded $50 \mu \mathrm{g}$ of total RNA was used for synthesis of cDNA probes. ${ }^{14,15}$

\section{Probe labelling and hybridization to DNA microarrays}

From each of the 50- $\mu \mathrm{g}$ RNA pools, a cDNA probe was synthesized using reverse transcriptase-polymerase chain reaction (RT-PCR) (Superscript, Gibco-BRL) and an 18-mer oligo-dT primer. For hybridization of the probes, we used a commercially available human microarray, UniGEM1 (Incyte Genmics, Fremont, CA, USA), containing 9700 human cDNA clones, $60 \%$ of them coding for known genes. During the RT reaction, the cDNA in the hybridization probe derived from the senile cataract sample was labelled with Cy3-dCTP

(Amersham) and the cDNA from the normal lenses with Cy5-dCTP (Amersham). ${ }^{14,15}$ Hybridization and subsequent scanning, visualization, and quantization of the results were performed using the GEMTools software (Incyte Genomics, Fremont, CA, USA). This software generates significant differences between gene expressions where, a two-fold difference is equal to a $P$-value of $0.05 .^{14-17}$ All differential expression values were log transformed and balanced, essentially as previously described. ${ }^{17}$ Briefly, the differential values were calculated only if the signal to background ratio exceeded 2.0, the signal intensity was above $200 \mathrm{U}$ in at least one of the two channels, and the element diameter exceeded $40 \%$ of the mean element diameter for the array.

\section{Results}

Anterior capsules from 27 clear lenses and from 108 lenses with senile cataracts were used for total RNA extraction. It should be stressed that RNA from lenses of the same cadaver was extracted separately, and separately assessed by ethidium bromide microgel, electrophoresed, scanned, and analysed for quality and quantity. In all, 12 of the 27 control cadaveric lenses were found to contain degraded RNA and were therefore excluded from further analysis. All 12 of these RNA samples had been obtained $4 \mathrm{~h}$ or more after death, whereas the rest of the cadaveric lenses used in this study, all of which contained RNA of good quality, had been obtained $3 \mathrm{~h}$ or less after death. Similarly, among the samples obtained from senile cataractous lenses only those containing nondegraded RNA were used for this study. Thus, although more cataract samples were initially collected, only 108 were included in the analysis.

Scanning of the microarray of 9700 clones with each of the hybridization probes revealed that 1827 clones showed a detectable hybridization signal with either the clear lens or the cataractous lens probe (See Figure 1). Expression of 400 of the clones in the control and the cataract-derived cDNA probes the differed by a factor of more than two. The differential in the fluorescent signal for a particular gene represents the actual mRNA level of these genes within each probe. A two-fold down- or upregulation is generally considered a significant result.

Three genes, filensin, inwardly rectifying potassium channel, and PEDF, were found to be substantially downregulated in senile cataract lenses. The differential expression pattern of each of these genes is recorded in Table 1. All three showed high fluorescent signals in clear lenses, and significantly lower signals in cataractous lenses.

\section{Discussion}

The results of this study showed that the filensin gene was downregulated 41. 3-fold in lenses with senile cataract. The primary sequence, secondary structure, and unique gene structure of the filensin human gene were described by Hess et al in 1998. ${ }^{18}$ The intermediate filament (IF) proteins of the lens form two morphologically distinct polymers: (a) $10 \mathrm{~nm}$ thick intermediate filaments and (b) beaded filaments, a highly specialized network of obligate heteropolymers juxtaposed to the plasma membrane, which is composed of two lens-specific polypeptides, filensin, and phakinin. ${ }^{19,20}$ Filensin is a $115-k D a$ cytoskeletal membranal protein. Indirect immunofluorescence and immunoelectron microscopy show that filensin appears to be concentrated at the periphery of the hexahedral LFCs. ${ }^{5}$ The cytoplasm of the LFCs is filled with crystallins, a class of water-soluble proteins believed to refract the light and minimize its scattering as it passes through the eye. ${ }^{1}$ Alpha B-crystallin, a small heat-shock protein expressed at high levels in the lens, selectively targets the intermediate filament proteins filensin and phakinin for protection against unfolding during conditions of stress, thereby protecting against cataract formation. $^{21}$

Filensin is believed to be functionally important in the differentiation of LFCs and the maintenance of their conformation and transparency. ${ }^{4,22,23}$ The intermediate filament vimentin does not appear to play a major role in lens function. Knockout of the lens' single vimentin gene in the mouse does not affect lens morphogenesis or the overall architecture of the LFCs. ${ }^{20}$ In contrast, reduced synthesis of filensin in a mutant mouse strain has been 


\section{Senile Cataract}

a

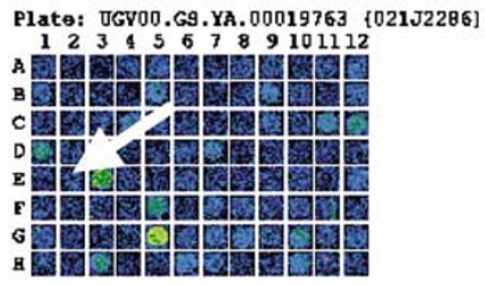

b

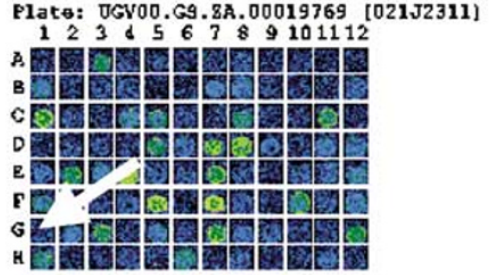

C

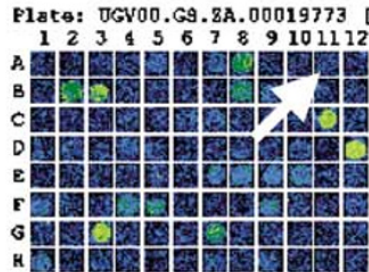

\section{Normal Lens}
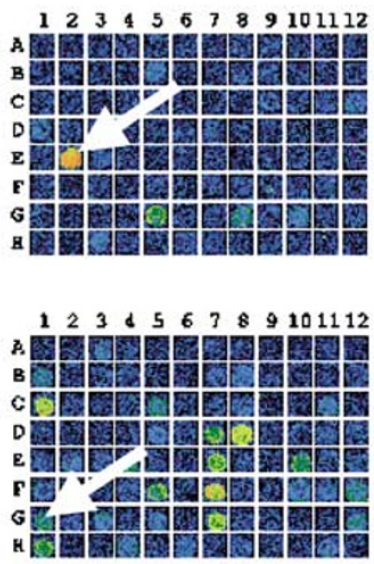

scale

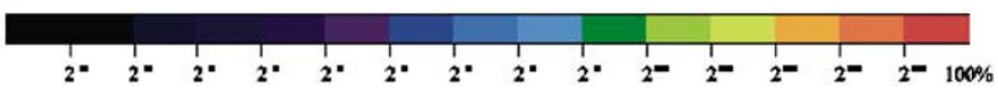

Figure 1 Differential expression of mRNA from lenses with senile cataract and from normal lenses, monitored on microarray. Fluorescent scans, represented by a pseudocolour scale, correspond to expression levels of mRNA derived from lenses with senile cataract and normal lenses. The colour bar was calibrated from the signal obtained using relatively high concentrations of known genes (performed according to Incyte; red is the strongest and black the weakest). Numbers and letters on the axes mark the position of each cDNA in the microarray. Arrows mark the location of cDNA clones for filensin (a, row E column 2), inwardly rectifying potassium channel (b, row G column 1), and PEDF (c, row A column 11).

Table 1 Strongly downregulated genes in lenses with senile cataract

\begin{tabular}{llccc}
\hline Gene Name & $\begin{array}{l}\text { Gene } \\
\text { accession }\end{array}$ & $\begin{array}{c}\text { Signal in } \\
\text { senile cataract }\end{array}$ & $\begin{array}{c}\text { Signal in } \\
\text { normal lens }\end{array}$ & $\begin{array}{c}\text { Differential expression } \\
\text { (cataract/normal) }\end{array}$ \\
\hline Homo sapiens filensin & $\mathrm{Y} 16717$ & 193 & 7979 & -41.3 \\
Homo sapiens inwardly rectifying potassium channel & AI087811 & 155 & 1055 & -6.8 \\
Pigment epithelium-derived factor & $\mathrm{U} 29953$ & 154 & 903 & -5.9 \\
\hline
\end{tabular}

correlated with severe developmental defects, such as the inability of the LFCs to elongate. ${ }^{24,25}$ The results of a recent analysis of the lens proteins from 10 young patients after cataract operations led to the suggestion that changes in cytoskeletal proteins may contribute to congenital and childhood cataracts. ${ }^{26}$ The results of the present study showed significant downregulation of the filensin gene in the senile cataract group. Given the importance of this lens cytoskeleton component in maintaining the conformation and transparency of the lens, it seems likely that the filensin gene plays a key role in cataract development, where the structure of the lens is disrupted.

In this study, the inwardly rectifying potassium channel gene was downregulated by 6.8 -fold in lenses with senile cataract. Potassium conductance is essential for maintenance of the volume and transparency of the lens. Three major potassium current channels exist in lens cells: (a) an outwardly rectifying current channel, (b) a calcium-activated current channel, a conductance channel that is activated by calcium at its inner surface and participates in cell signalling, transepithelial 
transport, and volume regulation, ${ }^{27}$ and (c) an inwardly rectifying current channel, comprising a family of more than 10 members. ${ }^{28}$ These three $\mathrm{K}^{+}$channels play a pivotal role in determining resting membrane potential, regulating action potential duration, and transporting $\mathrm{K}^{+}$ions, and therefore contribute substantially to the functioning of lens epithelial cells. ${ }^{29}$ The involvement of inwardly rectifying $\mathrm{K}^{+}$channel in cataract formation has not been documented. Retinal glial cells obtained from patients suffering from vitreoretinal or chorioretinal diseases show partial or complete loss of inwardly rectifying potassium currents. ${ }^{30}$ However, reduction in the expression of inwardly rectifying potassium channel gene in lens epithelial cells affects the morphology and transparency of the lens, and may therefore be associated with cataract formation.

The gene for PEDF was found to be downregulated 5.9-fold in lenses with senile cataract in our study. The retinal pigment epithelium (RPE) is a highly specialized neuroepithelium, which develops in advance of and lies adjacent to the interphotoreceptor matrix. The RPE, which plays a critical role in retinal homeostasis, synthesizes and secretes many soluble products into the interphotoreceptor matrix, among them $\mathrm{PEDF}_{,}^{8-10}$ a 50-kDa member of the serpin (serine protein inhibitor) family. PEDF is expressed intracellularly in almost all human ocular tissues and extracellularly during both foetal and early adult periods. ${ }^{8-10,31}$ It is also expressed by cells other than RPE, such as cultured foetal lung fibroblasts, where its downregulation is linked to the process of senescence. ${ }^{32}$ PEDF has been detected in the eyes of human fetuses at 17 weeks of gestation. Relative to this, PEDF secreted by human foetal RPE cells in culture was shown to induce neuronal differentiation of human retinoblastoma cells in vitro. ${ }^{33-35}$ It also acts as a survival factor, protecting neuronal cells from natural and induced apoptosis. ${ }^{33}$ The loss of PEDF in senescent cells and in differentiated retinoblastoma cells suggests that this protein might be involved in terminal differentiation and ageing. ${ }^{33}$ The association of intracellular PEDF with cytoskeletal structures and its colocalization with actin point to the possibility that it may be a microfilament-binding protein. Thus, PEDF could be involved in maintaining the stability of cytoskeletal structures. ${ }^{8}$ Taken together, the above findings strongly suggest that the observed downregulation of PEDF in lenses with senile cataract in the present study is likely to be relevant to cataractogenesis.

In summary, this study demonstrates a significant downregulation of three genes - filensin, inwardly rectifying potassium channel gene, and PEDF gene-in epithelial cells from lenses with senile cataract. Each of these genes has a key physiological and structural role in the lens. It thus seems that the underexpression of each of these genes can induce cataract formation. Moreover, their combined downregulation provides a possible mechanism for the disruption of lens morphology, which may lead to cataract. Further study of the effects of these genes, and of as yet uncharacterized genes that play different regulatory roles in the maintenance of lens physiology, is likely to provide new insights into the mechanism by which senile cataract is formed.

\section{References}

1 Kuszak JR. Embryology and histology of the lens. In: Tasman W, Jaeger EA, (eds). Duane's Clinical Ophthalmology Vol. I. Lippincot-Raven: Philadelphia, 1995; 1-9.

2 Bassnett S, Kuszak JR, Reinisch L, Brown HG, Beebe DC. Intercellular communication between epithelial and fibre cells of the eye lens. J Cell Sci 1994; 107: 799-811.

3 Kuszak JR. The ultrastructure of epithelial and fibre cells in crystalline lens. Int Rev Cytol 1995; 163: 305-350.

4 Masaki S, Kamachi Y, Quinlan RA, Yonezawa S, Kondoh H. Identification and functional analysis of the mouse lens filensin gene promoter. Gene 1998; 214: 77-86.

5 Merdes A, Brunkener M, Horstmann H, Georgatos SD. Filensin: a new vimentin-binding, polymerizationcompetent, and membrane-associated protein of the lens fibre cell. J Cell Biol 1991; 115: 397-410.

6 Clark JI, Matsushima H, David LL, Clark JM. Lens cytoskeleton and transparency: a model. Eye 1999; 13: 417-424.

7 Krausz E, Augusteyn RC, Quinlan RA, Reddan JR, Russell $\mathrm{P}$, Sax CM et al. Expression of crystallins, Pax6, filensin, CP49, MIP, and MP20 in lens-derived cell lines. Invest Ophthalmol Vis Sci 1996; 37: 2120-2128.

8 Tombran-Tink J, Shivaram SM, Chader GJ, Johnson LV, Bok D. Expression, secretion, and age-related downregulation of pigment epithelium-derived factor, a serpin with neurotrophic activity. J Neurosc. 1995; 15: 4992-5003.

$9 \mathrm{Wu}$ YQ, Becerra SP. Proteolytic activity directed toward pigment epithelium-derived factor in vitreous bovine eyes. Implications of proteolytic processing. Invest Ophthalmol Vis Sci 1996; 37: 1984-1993.

10 Steele FR, Chader GJ, Johnson LV, Tombran-Tink J. Pigment epithelium-derived factor: neurotrophic activity and identification as a member of the serine protease inhibitor gene family. Proc Natl Acad Sci USA 1992; 90: 1526-1530.

11 Li WC, Kuszak JR, Dunn K, Wang RR, Ma W, Wang GM et al. Lens epithelial cell apoptosis appears to be a common cellular basis for non-congenital cataract development in humans and animals. J Cell Biol 1995; 37: 169-181.

12 Li DW, Spector A. Hydrogen peroxide-induced expression of the proto-oncogenes, c-jun, c-fos and c-myc in rabbit lens epithelial cells. Mol Cell Biochem 1997; 137: 59-69.

13 Chylack Jr LT, Leske MC, McCarthy D, Khu P, Kashiwagi T, Sperduto R. Lens opacities classification system II (LOCS II). Arch Ophthalmol 1989; 107(7): 991-997.

14 Nowak R. Entering the postgenome era. Science 1995; 270: 368-369.

15 Schena M, Shalon D, Davis RW, Brown PO. Quantitative monitoring of gene expression patterns with a complementary DNA microarray. Science 1995; 270: 467-470. 
16 Schena M, Shalon D, Heller R, Chai A, Brown PO, Davis RW. Parallel human genome analysis: microarray-based expression monitoring of 1000 genes. Proc Natl Acad Sci USA 1996; 93: 10614-10619.

17 Yue H, Eastman PS, Wang BB, Minor J, Doctolero MH, Nuttall RL et al. An evaluation of the performance of cDNA microarrays for detecting changes in global mRNA expression. Nucleic Acids Res 2001; 29: E41.

18 Hess JF, Casselman JT, Kong AP, FitzGerald PG. Primary sequence, secondary structure, gene structure, and assembly properties suggest that the lens-specific cytoskeletal protein filensin represents a novel class of intermediate filament protein. Exp Eye Res 1998; 66: 625-644.

19 Prescott AR, Sandiland A, Hutcheson AM, Carter JM, Quinlan RA. The intermediate filament cytoskeleton of the lens: an ever-changing network through development and differentiation. A mini review. Ophthalmic Res 1996; 28: 58-61.

20 Georgatos SD, Gounari F, Remington S. The beaded intermediate filaments and their potential function in eye lens. Bioassays 1994; 16: 413-418.

21 Muchowski PJ, Valdez NM, Clark JI. AlphaB-crystallin selectively targets intermediate filament proteins during thermal stress. Invest Ophthalmol Vis Sci 1999; 40: 951-958.

22 Colucci-Guyon E, Portier MM, Dunia I, Paulin D, Pournin S, Babinet $C$. Mice lacking vimentin develop and reproduce without an obvious phenotype. Cell 1994; 79: 679-694.

23 Clark JI, Matsushima H, David LL, Clark JM. Lens cytoskeleton and transparency: a model. Eye 1999; 13: 417-424.

24 Masaki S, Tamai K, Shoji R, Watanabe T. Defect of a fibre cell specific 94-kDa protein in the lens of inherited microphthalmic mutant mouse Elo. Biochem Biophys Res Commun 1991; 179: 1175-1180.

25 Goulielmos G, Gounari F, Remington S, Muller S, Haner M, Aebi $\mathrm{U}$ et al. Filensin and phakinin form a novel type of beaded intermediate filaments and coassemble de novo in cultured cells. J Cell Biol 1996; 132: 643-655.
26 Matsushima H, Mukai K, Obara Y. Changes in cytoskeletal proteins in childhood cataract lenses. Jpn J Ophthalmol 2000; 44: 187-188.

27 Doupnik CA, Davidson N, Lester HA. The inward rectifier potassium channel family. Curr Opin Neurobiol 1995; 5: 268-277.

28 Horio $\mathrm{Y}$, Hibinio $\mathrm{H}$, Inanobe A, Yamada M, Ishii M, Tada $\mathrm{Y}$, Satoh E, Hata Y, Takai Y et al. Clustering and enhanced activity of an inwardly rectifying potassium channel, Kir4.1, by an anchoring protein, PSD-95/SAP90. J Biol Chem 1997; 272: $12885-12888$.

29 Ishii M, Horio Y, Tada Y, Yamada M, Ishii M, Tada Y et al. Expression and clustered distribution of an inwardly rectifying potassium channel, $\mathrm{K}_{\mathrm{AB}}-2 / \mathrm{Kir} 4.1$, on mammalian retinal Müller cell membrane: their regulation by insulin and laminin signals. J Neurosci 1997; 17: 7725-7735.

30 Francke M, Pannicke T, Biedermann B, Faude F, Wiedemann $\mathrm{P}$, Reichenbach A et al. Loss of inwardly rectifying potassium currents by human retinal glial cells in diseases of the eye. Glia 1997; 20: 210-218.

31 Tombran-Tink J, Pawar H, Swaroop A, Rodrigues I, Chader GJ. Localization of the gene for pigment epithelium-derived factor to chromosome 17p13.1 and expression in cultured human retinoblastoma cells. Genomics 1994; 19: 266-272.

32 Pignolo RJ, Cristolfalo VJ, Rotenberg MO. Senescent WI-38 cells fail to express EPC-1, a gene induced in young cells upon entry into the $G_{0}$ state. J Biol Chem 1993; 268: 8949-8957.

33 Tombran-Tink J, Johnson LV. Neuronal differentiation of retinoblastoma cells induced by medium conditioned by human RPE cells. Invest Ophthalmol Vis Sci 1989; 30: 1700-1707.

34 Tombran-Tink J, Chader GJ, Johnson V. PEDF: a pigment epithelium-derived factor with potent neuronal differentiative activity. Exp Eye Res 1991; 53: 411-414.

35 Tombran-Tink J, Li A, Johnson MA, Johnson LV, Chader GJ. Neurotrophic activity of interphotoreceptor matrix on human Y-79 retinoblastoma cells. J Comput Neurol 1992; 317: 175-186. 